Estudos de Psicologia

2001, Vol 18, ㄲo 3, 75-87

\title{
Hermenêutica, Linguagem e Psicologia ${ }^{1}$
}

\section{Lucas Vieira Dutra²}

\begin{abstract}
O artigo analisa aspectos teóricos da possibilidade de contribuição da Hennenêutica para a Psicologia, determinada por uma interface comum, a Linguagem. São apontadas algumas dimensões da linguagem que apresentam interessetanto paraaPsicologiaquanto para aatividade hermenêutica. Após umabreve apresentação histórica daabordagem hennenêutica com suas principais vertentes, édiscutido sucintamente o problema da Hennenêutica, comparando aspectossuametodologiacom as das propostas racionalistas e empiricistas. São apresentadas a atividade de interpretação neste contexto e a possibilidade de compreensão. O texto conclui que, no âmbito do Ser, a Hennenêutica pode oferecer algumas propostas metodológicas visando contornar certas dificuldades encontradas em outros posicionamentos teóricos. Neste particular, e em especial pela linguagem, a contribuição daHennenêutica para a Psicologia pode ser proveitosa, principalmente para o campo da Psicoterapia. Palavras-chave: Psicologia, hennenêutica, método hennenêutico, linguagem.
\end{abstract}

\begin{abstract}
Hermeneutics, Language and Psychology

This artic1eanalyses some theoretical aspects of the possibility of contribution of Henneneutics to Psychology, provided by Language, a common interface. It is pointed some language dimensions having interests both to Psychology and hermeneutical activity. After a historical review of the hermeneutical positioning and its principals schools, it is briefly discussed the Hermeneutical problem, comparing aspects of this methodology to the methodologies of rationalist and empiricist proposals. It is placed the interpretation activity in this realm and the possibility of understanding. The article concludes that, in the ground of Being, Henneneutics can provide methodological proposals in order to deal with some difficulties encountered in others theoretical domains. In this sense, and by virtue of language, Henneneutics' contribution can be useful, mainly in the field of Psychotherapy.

Key words: Psychology, hermeneutics, henneneutic method, language.
\end{abstract}

\section{Introdução}

Ocasionalmente se afirma que os estudantes de Psicologia devem, o quanto antes, tomar posição em favor da orientação teórica ' $x$ ' ou 'r' (ou ainda, 'z'). O pressuposto deste optaré que seria importante para a continuidade do apropriado aprendizado da Psicologia. Ainda que a necessidade de se realizar essa escolha seja bastante discutível quanto à sua hora e lugar, vê-se que o rol de teorias produtivamente 'disponíveis' para realizar uma adequada opção é limitado, seja pelo currículo acadêmico, seja pela tradição e/ou quantidade e qualidade de divulgação das diversas escolas e vertentes teóricas. Um posicionamento pouco divulgado é o da Hennenêutica, a arte e a ciência da interpretação. Este artigo visa discutir algumas de suas propostas para a Psicologia, tendo como elo de ligação a linguagem.

1. O autor agradece aos Profs. Mamo M. Amatuzzi e Regina P. Lima as sugestões para o aperfeiçoamento do texto, responsabilizando-se pelas imperfeições remanescentes. Correspondência: lucasdll@palm.com

2. Psicólogo e Professor Universitário. Aluno no Programa de Pós-Graduação (Doutorado) do Instituto de Psicologia e Fonoaudiologia da Pontifícia Universidade Católica de Campinas. 
Há tempos se questiona o fato de o comportamento humano poder ser explanado de modo satisfatório dentro, tão somente, do arcabouço teórico da ciência natural (LONDON, 1969; BECK, 1976; MAHONEY, 1974, 1991; MORA VIA, 1995), de tendência empiricista, se assim podemos nomear. Entre aqueles que não acreditam nesta possibilidade, alguns argumentam que a conduta do homem deve ser caracterizada essencialmente como consistindo de atos carregados de sentido, e não meros padrões de resposta (ver p. ex. TAYLOR, 1964; MOYA, 1990). O homem, dessa maneira, não apenas se 'comporta', ele comete ações. A ação humana, para esta vertente, seria considerada não somente em termos dos comportamentos, mas também a partir de uma consideração sobre os agentes, e das razões pelas quais o agente age, $\mathrm{e}$ razões não podem ser identificadas com as causas do mundo físico: comportamento não é um efeito produzido por uma condição antecedente, mas a conseqüência de uma interpretação (BOL TON, 1979). Dentro desta questão entre ciência natural e comportamento, LIMA (1977, p. 31) parece ilustrar essas dificuldades quando diz

... pois sendo a vida afetiva um fenômeno estritamente individual, não pode ser tratada em nível estrito de operacionalidade, na medida em que o operacional é, necessariamente, socializado.

Nesta perspectiva está embutida a noção, no nível humano, da racionalidade (LENNON, 1990), um dos pressupostos essenciais da atividade do estudioso (e do profissional) em Psicologia. Podemos averiguar diversos significados de 'racional'. Em alguns contextos ditos 'humanísticos', conforme coloca MOSTERÍN (1987, p. 17)

\begin{abstract}
...é freqüente caracterizar a razão como as capacidades de reflexão e linguagem tipicamente humanas e, em conseqüência, utilizar o adjetivo 'racional' como 'possuidor das capacidades intelectuais e lingüísticas próprias da espécie humana' .
\end{abstract}

No entanto, segundo este autor, essa noção de racionalidade é trivial e analítica, pois coloca racionalidade somente como elemento diferenciador do homem dos demais animais. O uso correto do adjetivo 'racional' deveria incluir o esclarecimento de como certas crenças, decisões e ações são racionais, e outras, não. Fica evidente aqui que a racionalidade deve pressupor o uso de razão, e que esta constitui uma condição necessária, mas não em si suficiente (McCARTHY, 1998, p. 74).

Somente, segundo MOSTERÍN (op. cit), do humano e de suas crenças, decisões e condutas tem sentido predicar racionalidade ou irracionalidade. No exemplo do A., o homem não é somente 'animal racional' e, sim, 'animal racional ou irracional': podemos ser racionais, andarmos de bicicleta ou escrevermos versos, mas não é de modo algum necessário - para sermos homens - que sejamos racionais, que andemos de bicicleta nem que escrevamos versos. Racionalidade para esse autor - posição que endossamos - não é uma faculdade, mas um método. A aplicação do método racional pressupõe determinadas faculdades, mas nenhuma faculdade em si vai garantir a aplicação do método racional (cf. McGINN, 1982, p. 75). E, se existe sentido em qualificar de racional (ou irracional) a conduta de entes inteligentes, segundo utilizem (ou não) sua inteligência em conformidade com as regras do método racional, necessário se faz reconhecer, portanto, que a mais aguda inteligência pode ser compatível com a mais crassa irracionalidade. 
Se a atividade humana pode ser pautada por determinada racional idade, é possível afirmar que o sujeito racional relaciona-se com os objetos do mundo fundamentalmente através da mediação da linguagem; ela é o meio pelo qual os sujeitos alcançam seus objetos (ROUX, 1977, p. 12). Em outros termos, pode-se considerar, em princípio, que a maior parte do relacionamento do homem com o mundo é estruturada pela linguagem (VIANA, 2000; DUTRA, 1996). É grande a tentação de proceder a um reducionismo aqui, tão marcante se mostra sua prevalência na vivência do homem. Ao consideramos o homem utilizando a linguagem, dizemos que ele faz uso de palavras, de conceitos, de significados, de sentidos: por meio disso tudo o homem tem acesso ao mundo; em outros termos, vem (bem ou mal) a conhecê-lo (STEIN, 1996, p. 16).

A investigação da linguagem é fundamental para a formação do Psicólogo e, na verdade, o estudante e o profissional sempre vão se deparar com esta área de debate, mesmo que não se proponham a examiná-lo especificamente, de modo sistemático, como um tema de estudo ou pesquisa. A linguagem enquanto fenômeno é objeto de análise entre os diversos tipos de estudiosos e, no plano humano, os mesmos têm a pretensão de alcançá-la, ainda que por diversas vertentes (MARCONDES, 1992; CHALUB, 1993; VANOYE, 1979; $\mathrm{KOCH}, 1992$; CHOMSKY, 1974). É uma função psicológica, para GUSDORF (1970, p. 05),

... correspondente à entrada em funcionamento de um conjunto de dispositivos anatômicos e fisiológicos, prolongando-se em montagens intelectuais,para se sistematizar num complexo exercício de conjunto, característico, entre todas as espécies animais, apenas da espécie humana. A língua é o sistema de expressão falada própria de tal ou tal comunidade humana. O exercício da língua produz, com a sua continuação, uma espécie de depósito sedimentar, o qual ganha valor de instituição e se impõe ao falar individual, sob as espécies de um vocabulário e de uma gramática. (...) $A$ linguagem e a língua são dados abstratos, condições de possibilidade da palavra, que as encarna, ao assumi-las, para as fazer passar ao acto. Existem apenas homens falantes, quer dizer, capazes de linguagem e situados no horizonte de uma língua. Há assim uma hierarquia de graus de significação, desde o simples som vocal, que se estiliza em palavras, pela imposição de um sentido social, até a palavra humana efetiva, carregada de intenções particulares, portadoras de valores pessoais.

A linguagem possui duas funções principais, segundo CARROLL (1977, p. 15): um sistema de respostas através do qual os indivíduos se comunicam - comunicação interindividual-, e um sistema de respostas que facilita o pensamento e a ação do indivíduo comunicação intra- individual. TERWILLIGER (1974, p. 27) adiciona a estas visões mais alguns aspectos:

Linguagem é um sistema de comportamentos e de comportamentos potenciais; esses comportamentos lingüísticos podem exercer influência sobre o comportamento de outras pessoas; comportamentos lingüísticos são relevantes ou adequados à situação-ambiente, mas, em parte, dela independem; e comportamentos lingüísticos podem revelar-se inapropriados ou errôneos. 
Existem outros posicionamentos sobre a linguagem, oriundos de tradições diversas, espelhando maneiras por vezes divergentes (do declinado acima) de explanar sobre o que seria o fenômeno lingüístico. Mas é inegável que o valor maior da linguagem consiste em permitir estender ao homem um valor do mundo. Este se torna acessível via estabelecimento de uma consciência de si como ser situado, possuidor de uma ferramenta de conhecimento: " $A$ virtude da linguagem (..) é a de constituir (..) um universo à medida da humanidade" (GUSDORF, 1970, p. 12). À parte os aspectos doutrinários de cada escola, subjacentes às diversas tradições e vertentes, o fenômeno lingüístico a que elas remetem ocorre em grupos sociais, em comunidades. Dentre uma ampla gama de aspectos que o fenômeno lingüístico pode denotar, o fato de o mesmo ocorrer no seio de agrupamentos humanos confere a ele o caráter de mutabilidade. CASSIRER (1972) escreve, à p. 181 do seu clássico Antropologia Filosófica, que

... a linguagem humana, desde o princípio, esteve sujeita à mudança e à decadência". Mais adiante, coloca que "A mudança - a mudança fonética, analógica, semântica - é elemento essencial da linguagem (p. 189).

Em suma, o uso da linguagem carrega em si o germe da mudança e, por extensão, da imprecisão, da redundância, da incorreção. $\mathrm{O}$ uso da linguagem deveria ser cercado de cuidado constante, visto a tendência a falhar ser-lhe como que intrínseco (cf. TRACY, 1997).

A questão do correto uso da linguagem se interpõe ao estudioso, mas não é, segundo nos parece, preocupação basilar para o homem comum. Para este, a crença de pertencer a uma comunidade lingüística comum o induz à crença adicional de compartilhar, em princípio, os mesmos conteúdos que, se não idênticos, ao menos seriam suficientemente assemelhados, 0 quanto favoreça o entendimento presumido entre os demais falantes (ADLER, 1996, p. 67). O que ocorre é a posse, entre as pessoas, de vocabulários afeitos a domínios distintos - apesar de similares - visto que as experiências de aquisição de linguagem são eminentemente idiossincráticas. Como observou CASSIRER (1972, p. 214):

"Os termos da linguagem comum não se medem pelos mesmos padrões daqueles com que expressamos conceitos científicos. Confrontadas com a terminologia científica, as palavras da linguagem comum revelam sempre certa vagueza; quase sem exceção, são tão indistintas e mal definidas que não suportam a prova da análise lógica".

O uso da linguagem, inevitavelmente, traz a tendência de sermos imprecisos, não só por causa da mutabilidade, mas também da maleabilidade do seu emprego (cf. AMATUZZI, 1989, Introdução). Como ferramenta, a linguagem é a melhor criação do homem, mesmo o que o distingue perante todos os demais animais; no entanto, possui vícios ocultos. FREGE explica como isto pode ocorrer:

"A linguagem não é regida por leis lógicas, de modo que a obediência à gramática já garantisse a correção formal do curso do pensamento. As formas em que se exprime a dedução são tão variadas, tão frouxas e flexíveis que facilmente podem insinuar, sem que se perceba, premissas que, em seguida, são ignoradas, no momento de enumerar as condições necessárias de validade da conclusão. (..) Não existe na linguagem um 
conjunto rigorosamente delimitado de formas de raciocínio, de modo a não se poder distinguir, pela forma lingüística, uma passagem sem lacunas de uma que omite membros intermediários". (FREGE, 1974,p.196) ${ }^{3}$

Consideramos que esse conhecimento lingüístico é altamente significativo na medida em que ele permite que o homem profira asserções acompanhadas de predicados (qualidades, atributos) - que podem ser verdadeiras ou falsas. Na medida em que o homem é capaz de fazer uso correto desses enunciados assertóricos predicativos (que, como dissemos, podem ter a propriedade de verdade e de falsidade), podemos afirmar, identicamente, que o homem é racional. E esta racionalidade é exercida, como vimos, sempre dentro de uma determinada cultura, no seio de uma história, imersa em um contexto. Existe um contexto que se coloca entre os objetos e a linguagem com que o homem se dirige a estes objetos, notadamente os objetos humanos. Por um lado, o homem, enquanto ser racional, pronuncia sentenças afirmativas ou negativas sobre o mundo, tal como se apresenta, e decide, mediante proposições práticas, aquilo que deve realizar (RYLE, 1980). Por outro lado, não basta ao sujeito ter a ferramenta da linguagem para bem conhecer o objeto, não basta saber simplesmente o significado, por mais que se atenha à lógica ou à estrutura cognitiva. Tem-se que averiguar o significado num mundo histórico determinado, contextualizado e, para tanto, necessária se faz a introdução do elemento interpretação, visando atingir a efetiva compreensão. Em outras palavras, constatando a potencialidade e as especificidades da natureza do fenô- meno da linguagem, auferimos que ela por si só não garante conhecer efetivamente o discurso daquele ser que pretende comunicar-se, aquele-que-dialoga. Precisamente neste ponto da contextualização acredita-se realizar uma necessária aproximação entre linguagem e hermenêutica (FIGUEIREDO, 1998, p. 12).

Resumindo, podemos afirmar que os modos pelos quais os objetosse dão aos homens constituem-se em linguagem e, complementarmente, assume-se que não exista experiência significativa que não seja mediada pela linguagem. Ese o mundo é vislumbrado sob a égide da racionalidade, significa abarcá-lo mediante a utilização de conceitos estruturados em um discurso que confere sentido às coisas deste mesmo mundo. A partir do significado destas coisas - dentro de um contexto - pode-se estruturar, mediante a interpretação, uma compreensão. E chegar precisamente a isto - compreensão, e não necessariamente a números ou freqüências - é o que visa a atividade hermenêutica. Uma abordagem hermenêutica abarca questões sobre verdade e enfatiza a intersubjetividade e a contextualização, colocando o intérprete no centro da construção do conhecimento (ATWOOD \& STOLOROW, 1984; ORANGE, 1995). Vejamos agora a abordagem hermenêutica.

O nome de Hermes, o mensageiro dos deuses gregos, originou hermeneuein (interpretar) e hermeneutike (a arte de interpretar) (HONDERICH, 1995). Esta tornou-se importante depois da Reforma, quando os protestantes necessitaram interpretar a Bíblia de modo mais acurado. A Hermenêutica medieval relacionava à Bíblia quatro níveis de significado: literal, alegórico, tropológico (moral) e anagó-

3. Ao que parece, o texto citado quer dizer, efetivamente,Não existe na linguagem um conjunto rigorosamente delimitado de formas de raciocínio, de modo a se poder distinguir, pela forma lingüística, uma passagem sem lacunas de uma que omite membros intermediários. 
gico (escatológico), mas os reformistas insistiam na exegese literal (ou 'gramatical') e o estudo do hebreu e do grego.

A percepção de que as expressões humanas contêm um componente de significação, que tem que ser reconhecido como tal por um sujeito e transposto para seu próprio sistema de valores e significados, deu origem ao problema da hermenêutica: saber como é possível esse processo e como tomar objetivas as descrições de sentido subjetivamente intencionais, tendo em conta o fato de passarem pela subjetividade do próprio intérprete (BLEICHER, 1992, p. 13). Em termos genéricos, Hermenêutica pode ser entendida como a teoria ou a filosofia da interpretação do sentido (idem, ibidem), porém ela enquanto tal, desafia uma direta e concisa definição (MESSER et al, 1990, p. 2). Para aproximarmos afirmativas nesse sentido, necessitamos estabelecer algumas diferenciações, particionando a esfera hermenêutica em três áreas (ou tendências, conf. BLEICHER, idem): hermenêutica metodológica (ou teoria hermenêutica), hermenêutica ontológica (ou filosofia hermenêutica), e hermenêutica crítica. [Esta diferenciação não é consensual. PALMER (1988, p. 33), p. ex., identifica seis áreas, que originam seis definições].

Hermenêutica metodológica refere-se às abordagens cuja meta específica é reformar, ampliar e humanizar. Debruçam-se sobre a problemática de uma teoria geral da interpretação, como metodologia das Geiteswissenshaften Ciências (ditas) Humanas, que incluem as ciências sociais - todas as disciplinas focadas no entendimento dos escritos, das ações e das artes do homem. Aborda' formas significativas' com um conjunto de normas formuladas com vista a facilitar a interpretação correta das objetivações da atividade ou consciências humanas. Costumeiramente autores dessa tradição assumem, como Dilthey, que métodos apropriados para as Ciências Humanas vão divergir daqueles das Ciências Naturais. A Hermenêutica ontológica constitui a filosofia da compreensão, quecomeça com os escritos de Heidegger. Ela emprega métodos fenomenológicos, vendo compreensão como um modo fundamental de ser-na-mundo e, mediante um explorar da natureza da interpretação, procura pelas verdades fundantes para a clarificação da natureza de toda inquirição, incluindo a ciência. A filosofia hermenêutica não visa um conhecimento objetivo recorrendo a processos metodológicos, mas a explicação e descrição da existência humana (Dasein), na sua temporalidade e historicidade (BLEICHER, 1992, p.15). A Hermenêutica crítica tem seu maior representante em Habermas, que desafia os pressupostos idealistas subjacentes tanto à teoria hermenêutica quanto à filosofia hermenêutica: a não-consideração de fatores extralingüísticos como o trabalho e o domínio, que ajudam também a construir o contexto do pensamento e da ação. Não bastasse isso, questiona-se se é justificável a filosofia hermenêutica reivindicar uma universalidade quando considera a tradição inserida na linguagem como formando um consenso corroborante em si mesmo e inquestionável, visto proporcionar as condições para sua concretização (idem, p. 17). Em outras palavras, esta vertente hermenêutica conduz à atividade que visa criticar e expor os fundamentos ideológicos de todas as práticas sociais, como, p. ex., as atividades política e científica. Em particular, procura revelar fontes de dominação e de coerção que obstruem tanto o discurso aberto e o livre exercício da razão, como o fortalecimento das possibilidades da auto-determinação humana. 
A Hennenêutica, enquanto empreendimento intelectual humano, constitui atualmente um dos ramos mais importantes para a compreensão do homem, não obstante possuir algumas variantes. Grosso modo, podemos dizer que a mesma percorreu, em tempos recentes, três fases.

A primeira, com Friedrich E. D. Schleiennacher (1768-1834), o grande teólogo protestante e estudioso de Platão, que pronunciou suas famosas palestras a partir de 1818 , delineando uma teoria sistemática da interpretação de textos e da fala.O objetivo do interpretador é compreender diretamente o texto, igualmente ou até melhor do que seu autor. Desde que não se tem conhecimento direto do que estava na mente deste, deve-se tentar estar cônscio das muitas coisas de que mesmo ele, o autor, poderia estar não-consciente, excetuando-se ao menos o fato de o mesmo refletir sobre seu próprio trabalho e tornar-se seu próprio leitor (SCHLEIERMACHER, 1999). Nessa visão, um texto é interpretado a partir de dois pontos de vista: 'gramatical', relacionando-se com a linguagem em que é escrito, e 'psicológico', em relação à mentalidade e ao desenvolvimento do autor. Não se pode ter completa compreensão de ambos os aspectos desde que não se tenha conhecimento completo da linguagem ou da pessoa. Portanto, avança-se e recua-se entre os lados gramaticais e psicológico, e nenhuma regra pode estipular exatamente como realizar isso. A partir disso, em cada nível está-se envolvido num circulo hermenêutico, uma contínua reciprocidade entre parte e todo.

A segunda fase ocorre com o biógrafo de Schleiennacher, Dilthey (1833-1911), que veio a estender a Hennenêutica ao entendimento de todo comportamento humano e seus produtos. Na sua proposta de um 'método de compreensão', o entendimento de um autor, artista ou agente histórico não é direto, mas por meio de analogias com a própria experiência daquele que estuda, daquele que pesquisa. No entanto, a base psicológica e subjetiva desse processo foi posteriormente substituída, deixando o método de compreensão de ser a tentativa de encontrar a idéia ou a modificação mental que foi a causa da expressão, transformando-se na localização da expressão no quadro de referência objetivo do significado humano, para o qual contribuem tanto o contexto como a linguagem e o ambiente da cultura. Assim, o processo da metodologia da compreensão proposto por Dilthey nunca está completo, já que sempre pode desvelar-se outra dimensão no modo como os significados se ligam (BLACKBURN, 1997, p. 102).

A terceira fase ocorre com Heidegger (1889-1976), que aprendeu Hermenêutica mediante o seu treino teológico com Dilthey. A Hennenêutica teológica considerou a interpretação de textos antigos; Dilthey preocupou-se em entender o cultural em contraste com a ciência natural e, principalmente mas não exclusivamente, com a interpretação dos produtos das sociedades passadas. Agora, especialmente no Ser e Tempo (HEIDEGGER, 1989) - obra que influenciou um dos maiores hermeneutas modernos, Hans-Georg Gadamer (GADAMER, 1999) - Hennenêutica adquire um senso mais profundo e amplo. Esta atividade está relacionada com a interpretação do Ser da pessoa que interpreta textos e outros artefatos, que pode ser, p. ex., tanto um investigador cultural quanto um cientista natural. Heidegger realiza uma filosofia hennenêutica buscando interpretar o Dasein ('Ser-aí'), ampliando a discussão ao processo de constituição ontológica do homem, o que o constitui enquanto tal, posto que o homem é o único ente que fala e que, por isso, interrogando sobre si e sobre o mundo, possui a possibilidade de abertura ao Ser (BRUNS \& TRINDADE, 2001, p. 71). A partir desta visão heideggeriana, a abordagem da existência 
humana deve ser hermenêutica desde que os seus aspectos fundamentais não constituem um campo aberto, mas 'escondido', oculto, devido em parte à sua especificidade, em parte à tendência do Dasein em distorcer e obscurecer sua própria natureza e características.

Sob Heidegger, Hermenêutica ainda não apresenta regras ou uma teoria do interpretar: é a interpretação do Dasein. Mas a fenomenologia hermenêutica fornece um meio para a compreensão, desde que a característica central do Daseiné procurar entender a si e seu entorno, não no senso de uma interpretação desinteressada ou na emissão de uma asserção explícita, mas vislumbrando 'possibilidades' disponíveis a ela; enxergando um martelo, p. ex., como algo relacionado a consertar uma cadeira: todo simples pré-predicativo 'ver' do mundo invisível das disponibilidades é em si ao mesmo tempo um ver 'interpretador-compreensivo'. É por causa do fato de o Dasein possuir esta pré-compreensão que ele pode interpretar textos alheios e compreender a si. Para Heidegger as palavras 'mostram', além de si mesmas, denominado ser, e necessita-se refletir sobre isso, não simplesmente sobre o texto, de modo a compreender o que é dito.

Modernamente, alguns estudiosos identificam outras variantes da inquirição hermenêutica, tais como as hermenêuticas materialistas de Sandkühler e a de Lorenzer, e a hermenêutica fenomenológica de Paul Ricoeur (CESAR, 1998).Em suma, hermenêutica refere-se a um método de interpretação, primeiro de textos, depois do universo social, histórico e psicológico e, posteriormente, do Ser. Sua subjetividade inevitável contrasta com o método científico objetivo.
Retomando a discussão do inicio de nosso texto, as ciências naturais têm, por princípio, o escopo de afastar quaisquer indícios de subjetividade. Tal empreitada, no âmbito da Psicologia, traz dificuldades adicionais pelo fato de existirem inegavelmente muitos eventos (p. ex., o sentido do fazer humano ou mesmo os estados da Consciência) não alcançados por um programa que, na pretensão de ser científico, não produz alternativa universalmente aceitável para a explanação dos mesmos. Ao procurar um fundamento que viabilize a construção de um edifício, uma construção fixa, a psicologia objetivante, racional ou empiricista, necessita lançar mão de um projeto que satisfaça os critérios da unificação de todas as ciências, acumulando e sistematizando conhecimentos (PACKER \& ADDISON, 1989, p. 35). Pelo que vimos até aqui, a visão hermenêutica questiona a pretensa auto-suficência de tal empreendimento, visto que não vislumbra construir um arcabouço 'quase acabado' numa estrutura, mas sim trabalhar para manter a discussão aberta e vívida, sem perder a habilidade de encontrar novos desafios ou intuir novas charadas. A atividade hermenêutica envolve o reconhecimento de que o observador é normalmente parte (ao invés de estar destacado de) do que está sendo observado (BETAN, 1997, p. 353).

Metodologicamente as visões racionalistas, impiricistas e hermenêuticas podem ser comparadas (V. tabela 1) em quatro áreas: em termos do tipo de domínio a que a discussão específica se dirige (objeto); a origem ou fonte do conhecimento; a forma de explanação que é vista como a meta da discussão, e a maneira com que a inquirição é julgada mais apropriada (método). 
Tabela 1. Comparação entre as perspectivas empiricista, racionalista e hermenêutica (adaptado de PACKER \& ADDISON, 1989, p. 16)

\begin{tabular}{|c|c|c|c|}
\hline Aspecto & Empiricismo & Racionalismo & Hermenêutica \\
\hline Dominio & $\begin{array}{c}\text { Entidades independentes com } \\
\text { propriedades absolutas }\end{array}$ & $\begin{array}{c}\text { Estruturas formais } \\
\text { subjacentes a aparências }\end{array}$ & $\begin{array}{c}\text { Ação em contexto, textos e } \\
\text { análogo de textos }\end{array}$ \\
\hline Fonte do conhecimento & $\begin{array}{l}\text { Fundamentação providenciada por } \\
\text { fatos livres de interpretação; } \\
\text { dados brutos }\end{array}$ & $\begin{array}{l}\text { Fundamentaçăo provida } \\
\text { por axiomas e principios }\end{array}$ & $\begin{array}{l}\text { Compreensio prática, } \\
\text { correlacionada e articulada, } \\
\text { prové um ponto de partida }\end{array}$ \\
\hline Caráter da explanaçầo & $\begin{array}{c}\text { Afirmaçōes de regularidade entre } \\
\text { dados, leis causais }\end{array}$ & Formalizaçâo & $\begin{array}{l}\text { Registros narrativos, } \\
\text { leitura do texto }\end{array}$ \\
\hline $\begin{array}{l}\text { Método: relacionamento } \\
\text { com o pesquisado }\end{array}$ & $\begin{array}{l}\text { Objetivo, postura neutra } \\
\text { quanto a valores }\end{array}$ & $\begin{array}{l}\text { Abstraçĩo do contexto; } \\
\text { af́astamento }\end{array}$ & $\begin{array}{l}\text { Familiaridade com práticas; } \\
\text { participaçấo na cultura } \\
\text { compartilhada }\end{array}$ \\
\hline $\begin{array}{l}\text { Método: justificaçāo } \\
\text { da explanaçito }\end{array}$ & $\begin{array}{l}\text { Juizo correspondente } \\
\text { com a realidade }\end{array}$ & $\begin{array}{l}\text { Correspondêneia do juizo com } \\
\text { as intuiçōes da pessoa que julga }\end{array}$ & $\begin{array}{l}\text { Considera de que modo inter- } \\
\text { pretaçáo revela a resposta à } \\
\text { preocupação que a motivou }\end{array}$ \\
\hline
\end{tabular}

Pela análise dos aspectos identificados, vemos que essas perspectivas esposam premissas ontológicas e epistemológicas por vezes incompatíveis, ensejando a adoção de posicionamentos sobre o homem e a Ciência que influenciam toda a construção de um conhecimento. Isto pode parecer determinar ao estudante a necessidade de tomada de posição, se averiguarmos a necessidade de se guardar coerência e sistematicidade, tanto dentro de uma prática profissional, quanto à implementação de aspectos metodológicos de pesquisa. O problema que identificamos é justamente este: o entendimento do que é o homem e sua natureza fica de igual modo influenciado indelevelmente por essas questões 'metodológicas', processológicas, influência contra a qual poucos se acautelam. Quando se observam as diferenças marcantes que distinguem as 'linguagens' possuídas pelas pessoas, olhar-se para condutas descontextualizadas invariavelmente pode levar o profissional ou estudioso a equívocos sobre o que constitui significação para determinada pessoa, em determinada situação, para determinado problema ou vivência. Parece-nos que este aspecto é em si evidente, em especial na situação de Psicoterapia.
É encontradiça na literatura de pesquisa interpretativa a manifestação de um certo 'alívio' sobre a questão da metodologia (causada pelas exigências de procedimentos e técnicas da psicologia tradicional científica), que não é posta no âmbito hermenêutico (PACKER \& ADDISON, p. 32). Mesmo alguns adeptos desta visão hermenêutica sustentam que a mesma não tem método, visto que, como GADAMER (1999), acreditam que o problema da hermenêutica vai além dos limites do que o conceito de método estabelece para a ciência moderna. Por outro lado, podemos considerar, grosso modo, que o método científico originado pela visão empiricista não constitui, em verdade, um procedimento ou técnica 'livre' de interpretação, na medida em que estabelece um ponto de vista e avalia os registros oriundos, determinados por esta visão (ver p. ex., STEIN, 1996, p. 85).

Na verdade, o que Gadamer propõe é que seja alterado o que entendemos por método'. Existe procedimento, mas não sob a égide de objetividade e distanciamento e, aqui, avaliação não assume a forma de validação: na hermenêutica, o ponto devista do pesquisador e 
a avaliação de relatos explanatórios não são vistos como separados, mas em constante diálogo (idem, ibidem, p. 99). Ao invés de fins opostos num contínuo, estão como que num círculo, um círculo hermenêutico (ver Figura 1). A inquirição interpretativa enfoca efetivamente a atividade humana situada no contexto e nos resultados de tal atividade: instituições, história, relatos, registros, textos, histórias, vivências, vida.

Adiciona à compreensão do todo

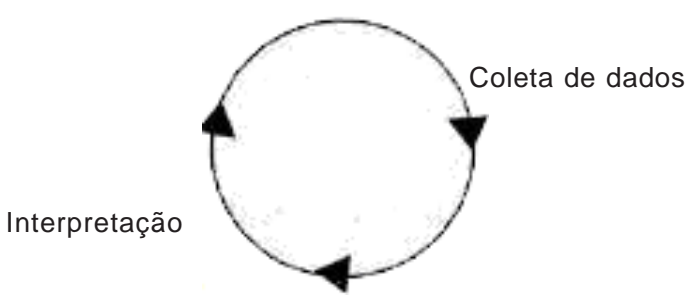

Figura 1. Método hermenêutico básico

('círculo hermenêutico')

(baseado em MICHRINA \& RICHARDS, 1996).

O círculo hermenêutico é ontológico na medida em que parte de uma situação comum que nos liga à tradição em geral e à do nosso objeto de interpretação em particular, estabelecendo a ligação entre finalidade e universalidade e entre teoria e praxis -mais que simplesmente epistemológico ou metodológico (na interpretação, um todo é considerado em relação às suas partes e vice-versa). Neste círculo hermenêutico, há acomodação e assimilação. Observamos aqui uma grande diferenciação com relação aos procedimentos do método científico, na medida em que ocorre nestes um 'círculo' de atividades radicamente diverso: Formar hipóteses - escoIher variáveis - definir variáveis - elaborar o design da pesquisa - selecionar a amostra coletar dados - analisar dados - testar hipóteses - interpretar resultados - confrontar/elaborar Teoria - Formar hipóteses...
Uma chave para o entendimento desta atividade nos é dada por GADAMER (1999), que centraliza o exame da experiência hermenêutica na crítica do conceito prevalecente ('científico') de experiência, orientado em demasia para o conhecer como ato perceptual e conhecimento como corpo de dados conceituais (PALMER, 1988, p. 194). Conhecer não seria simplesmente um fluxo de percepções, mas um acontecimento, um evento, um encontro, uma abertura frente aos desafios e perigos, originados em parte pelas expectativas que se possa ter. No experienciar a pessoaquestiona. Questiona em buscade respostas. Enestequestionar-e-responder, a linguagem assume papel preponderante. Linguagem como algo inseparável do pensamento e da compreensão, linguagem como meio que desvela o mundo.

Nesta visão, o modo de investigar condutas transmuta-se então em investigação do humano, do Ser e, dentre as diversas metodologias, a abordagem hermenêutica parece guardar amplas potencial idades de realização. Como vimos, a linguagem é a grande via de acesso; constitui mesmo o elemento fundamental para o endereçamento da atividade hermenêutica. Como indica RORTY (2000, p. 12), o homem não pode compreender nada sobre um objeto, a não ser que este objeto seja 'lido', que passe por uma descrição. As sentenças que se podem asseverar algo vão se relacionar com as demais sentenças já proferidas anteriormente sobre este algo e, caso pretenda-se estabelecer ligações legítimas entre essas afirmações sobre o objeto, depreende-se que a verdade surgirá somente da verdade que se possa estabelecer entre estas sentenças.

Disponibilizar descrições sobre o objeto significa possibilitar ao homem apreender este objeto; significa poder ele declarar algo a mais sobre o mesmo, a partir do que já dispõe, mesmo que seja relatar as mesmas coisas de antes, mas 
sob uma nova forma. Em outros termos, se aumenta-se a quantidade de descrições sobre um determinado objeto - e se elas guardam integração ou interassimilação - melhor se compreende o objeto (e a capacidade do homem redescrever ou recontextualizar um objeto é praticamente infinita). Não necessariamente precisa-se aumentar a 'profundidade' do conhecimento,ou qualquer outra metáfora de que se lance mão, para melhor 'compreender' algo. No nível do humano, do Ser, essas descrições assumem caráter fundamental. Existe uma frase muito famosa de GADAMER (1999), que sintetiza muito do que se disse até aqui: "O Ser que pode ser compreendido é linguagem". Averiguando-se as dificuldades inerentes que a linguagem propicia, masassuastambéminesgotáveis possibilidades, pode-se dimensionar ovalor do que a abordagem hermenêutica facilita para o estudioso e para 0 profissional, no inquirir da natureza e das implicações deste 'humano'.

Concretamente, para o estudante de psicologia, libertar-se de condicionantes pretensamente didático-propedêuticos, como ter ou não que 'escolher' entre esta ou aquela tradição ou inclinação teórica, parece-nos agora uma questão mal posta. Obviamente deve-se propugnar para construir uma bagagem intelectual e prática que instrumentalize o profissional a melhor servir o usuário de sua atividade, e não meramente filiar-se a esta ou aquela escola de pensamento. São questões importantes para o estudante (e para o profissional), mas, para a compreensão do humano, não compõem o fulcro. Parece-nos que a atividade hermenêutica pode prover salvaguardas contra estes e outros desvios assemelhados. Não bastasse isso, como proceder profissional ou científico, fornece ferramental apropriado para abordar a pessoa que se nos apresenta em encontro. Especificamente, p. ex., para a psicoterapia vislumbra-se um campo natural de aplicação da abordagem hermenêutica (JANIK, 1988), abarcando inclusive ali a possibilidade de questionar aspectos éticos (BETAN, 1997).

Ainda que se possa observar ao longo da história questionamentos sobre a interpretação em geral e aspectos da atividade hermenêutica em particular (LANCEROS, 1997) modernamenteostatus daHermenêuticaestápresenvado, porquanto nela reside o lugar onde se constitui a verdade possível (parcial e episódica), dado que o homem e o mundo são, do ponto de vista das ciências da cultura/ciências do espírito, conjuntos significativos, formas simbólicas ou urdidura de sentido em que coincidem, inevitavelmente, pensamento, linguagem e interpretação. Assim, neste âmbito, nesta convergência homem-mundo, cremos constituir, mediante a atividade hermenêutica, um espaço natural para auferirem-se contribuições valiosas para a Psicologia.

\section{Referências Bibliográficas}

Adler, M. 1. (1996) Ten philosophical mistakes. New York: Touchstone.

Amatuzzi,M. M. (1989)Oresgate dafala autêntica. Campinas: Papiros.

Atwood, R. D.\& Storo1ow, G. E. (1984). Structures of subjectivity: Explorations in psychoanalytic phenomenology. Hi1sda1e, NJ: The Analytic Press.

Beck, A. T. (1976). Cognitive therapy and the emotional disorders. New York: International Universities Press.

Betan, E. J. (1997). Toward a Hermeneutic Model of Ethical Decision Making in Clínical Practice. Ethics \&Behavior, 7(4),347-365.

Blackburn, S. (1997). Dicionário Oxford de Filosofia. Rio de Janeiro: Jorge Zahar Editor.

Bleicher, J. (1992). Hermenêutica contemporânea. Lisboa: Edições 70. 
Bolton, N. (1979). Philosophical problems in Psychology. London: Methuen.

Bruns, M.A. de T.\&Trindade, E. (2001).Metodologia fenomenológica: A contribuição da ontologia-hermenêutica deMartin Heidegger. In:M. A. de T. BRUNS \& A. F. de HOLANDA (Orgs.), Psicologia e pesquisa fenomenológica: Reflexõese perspectivas. São Paulo: Ômega Editora.

Carroll, J. B. (1977). Psicologia da linguagem (3 ${ }^{a}$ ed.). Rio de Janeiro: Zahar.

Cassirer, E. (1972). Antropologia filosófica. Ensaio sobre o homem - Introdução a uma filosofia da cultura humana. São Paulo: Mestre Jou.

Cesar, C. M. (Org.) (1998). PaulRicoeur-Ensaios. São Paulo: Paulus.

Chalub, S. (1993). Funções da linguagem (6a ed.). São Paulo: Ática.

Chomsky, N. (1974). Language and the mind. In: J. B. Maas (Ed.), Readings in psychology today. (3rd ed., pp. 146-151). Del Mar, Califomia: CRM/Ziff-Davis Publishers.

Dutra, L. V. (1996). O dualismo mente-corpo:Implicações para a prática da atividade física. Instituto de Biociências/UNESP - Campus de Rio Claro, sr. Dissertação de Mestrado em Ciências da Motricidade.

Figueiredo, R. M. (1998). Lingüística peirceana e teoria funcional. Scripta. Revista da Faculdade 'Auxilium' de Filosofia, Ciências e Letras de Lins, 1, (1),9-15.

Frege, G. (1974). Sobre a justificação científica de uma conceitografia. Coleção Os Pensadores (Vol. XXXVI). São Paulo: Abril SA Cultural e Industrial (Original de 1884).

Gadamer, H-G. (1999). Verdade e método - Traços fundamentais de uma hermenêutica filosófica (3ª ed.). Petrópolis: Vozes. (original alemão 1986).

Gondin, J. (1999). Introducción a la hermenéutica filosófica. Barcelona: Herder. (original alemão de 1991).

Gusdorf, G. (1970). A fala. Porto: Edições Despertar.
Heidegger, M. (1989). Ser e tempo (Vol. 2, $3^{\mathrm{a}}$ ed.). Petrópolis: Vozes (parte le 11.Original alemão de 1926; $16^{\text {a }}$ ed. revisada, 1986).

Honderich, T. (1995). The oxford companion to philosophy. New York: Oxford University Press, Inc.

Janik, A. (1988, Sept). Self-deception, naturalism, and certainty: Prolegomena to a critical hermeneutics. Inquiry, 31, (3), 295-305.

Koch, I. G. V. (1992).A interação pela linguagem. São Paulo: Contexto.

Lanceros, P. (1997). Antropología hermenéutica. Intersticios, 3, (7), 9-28.

Lennon, K. (1990). Explaining human action. La Salle, 111.: Open Court.

Lima, L. de O. (1977). Prefácio. In: J. ROUXA, 1rracionalidade em Psicologia (pp.17-31). Petropolis: Vozes.

London, P. (1969). Behavior control. New York: Harper \& Row, Publishers.

Mahoney, M. J. (1974). Cognition and behavior modification. Cambridge, Mass.: Ballinger.

Mahoney, M. J. (1991). Human change processes: The scientific fundations of psychotherapy. New York: Basic.

Marcondes,D. (1992). Filosofia, linguageme comunicação (2 ${ }^{\mathrm{a} e d}$. cevoampl.). São Paulo: Cortez.

Mc Carthy, D. (1998, April). Actions, beliefs, and consequences. Philosophical Studies, 90, (1), 57-77.

McGinn, C. (1982). The character of mind. Oxford, UK: Oxford University Press.

Messer, S. B., Sass, L. A. \& Woolfolk, R. L. (Eds.) (1990).Hermeneutics and psychological theory: interpretative perspectives on personality, psychotherapy, and psychopathology. New Brunswick: Rutgers University Press. Second paperback printing.

Michrina, B. P. \& Richards, C. (1996). Person to person - Fieldwork, dialogue, and the hermeneutic method. Albany, N.Y.: State University of New York. 
Moravia, S. (1995). The enigma of the mind: the mind-body problem in contemporary thought. Cambridge: Cambridge University Press.

Mosterín, J. (1987). Racionalidady acción humana ( $2^{\mathrm{a}}$ ed.). Madrid: Alianza Editorial.

Moya, C. J. (1990). Thephilosophyofaction-An introduction. Cambridge, UK: Polity Press.

Orange, D. M. (1995). Emotional understanding: Studies in psychoanalytic epistemology. New York: Guilford.

Packer, M. J. \&Addison, R. B. (Eds.) (1989). Entering Ihe circle - Hermeneutic investigation in psychology. Albany, N.Y: State University of New York Press.

Palmer, R. E. (1988).Hermeneutics - Interpretation theory in Schleiermacher, Dilthey, Heidegger, and Gadamer. Eighth printing. Evanston: Northwestem University Press.

Rorty, R. (2000, Fev. 13). A utopia de Gadamer. Folha de São Paulo. Caderno MAIS!, 418, domingo, 10-14.

Roux, J. (1977). A irracionalidade em Psicologia. Petrópolis: Vozes.
Ryle, G. (1980). Expressõessistematicamenteenganadoras e outros ensaios ( $2^{\mathrm{a}}$ ed.). Coleção Os Pensadores. São Paulo: Abril SA Cultural e Industrial.

Schleiermacher, F. D. E. (1999). HermenêuticaArte e técnica da interpretação. Petrópolis: Vozes. (original alemão Hermeneutik, 1959, com textos de 1805a 1833).

Stein, E. (1996). Aproximações sobre Hermenêutica. Porto Alegre: EDIPUCRS.

Taylor, C. (1964). The explanation of behavior. London: Routledge and Kegan Paul.

Terwilliger, R. F. (1974). Psicologia da linguagem. São Paulo: Cultrix/EDUSP.

Tracy, D. (1997). Pluralidad y ambigüedad hermenéutica, religión, esperanza. Madrid: Editorial Trotta.

Vanoye, F. (1979). Usos da linguagem. São Paulo: Martins Fontes.

Viana, M. (2000, dezembro). O papel da família no processo de aquisição da linguagem [número especial]. Revista Symposium - Ciências, Humanidades e Letras, 4, 35-38. (Universidade Católica de Pernambuco). 